\title{
Human bone marrow mesenchymal stem cells secrete endocannabinoids that stimulate in vitro hematopoietic stem cell migration effectively comparable to beta-adrenergic stimulation
}

\author{
Sevil Köse ${ }^{a}$, Fatima Aerts-Kaya ${ }^{a}$, Çağla Zübeyde Köprï̈ ${ }^{b}$ Emirhan Nemutluc, Barış Kuşkonmaz ${ }^{\mathrm{d}}$, \\ Beren Karaosmanoğlu ${ }^{a}$, Ekim Zihni Taşkıran ${ }^{\mathrm{e}}$, Belgin Altun ${ }^{\mathrm{f}}$, Duygu Uçkan Çetinkaya ${ }^{\mathrm{a}, \mathrm{d}}$, and \\ Petek Korkusuz ${ }^{\mathrm{g}}$
}

${ }^{a}$ Department of Stem Cell Sciences, Institute of Health Sciences, Center for Stem Cell Research and Development (PEDI-STEM), Hacettepe University, Ankara, Turkey; ${ }^{\mathrm{b}}$ Department of Histology and Embryology, Faculty of Medicine, Yuksek Ihtisas University, Ankara, Turkey; ${ }^{\mathrm{c}}$ Department of Analytical

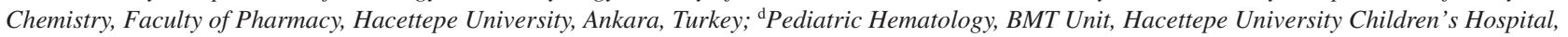
Ankara, Turkey; ${ }^{\mathrm{e}}$ Department of Medical Genetics, Faculty of Medicine, Hacettepe University, Ankara, Turkey; ${ }_{\mathrm{f}}^{\mathrm{f}}$ Department of Microbiology, Faculty of Medicine, Hacettepe University, Ankara, Turkey; ' Department of Histology and Embryology, Faculty of Medicine, Hacettepe University, Ankara, Turkey

(Received 30 March 2017; revised 27 September 2017; accepted 27 September 2017)

\begin{abstract}
Granulocyte colony-stimulating factor (G-CSF) is a well-known hematopoietic stem cell (HSC)mobilizing agent used in both allogeneic and autologous transplantation. However, a proportion of patients or healthy donors fail to mobilize a sufficient number of cells. New mobilization agents are therefore needed. Endocannabinoids (eCBs) are endogenous lipid mediators generated in the brain and peripheral tissues and activate the cannabinoid receptors CB1 and CB2. We suggest that eCBs may act as mobilizers of HSCs from the bone marrow (BM) under stress conditions as beta-adrenergic receptors $(\operatorname{Adr} \beta)$. This study demonstrates that BM mesenchymal stem cells (MSCs) secrete anandamide (AEA) and 2-arachidonylglycerol (2-AG) and the peripheral blood (PB) and BM microenvironment contain AEA and 2-AG. 2-AG levels are significantly higher in PB of the G-CSF-treated group compared with BM plasma. BM mononuclear cells (MNCs) and CD34 ${ }^{+}$HSCs express CB1, CB2, and Adr $\beta$ subtypes. CD34 ${ }^{+}$HSCs had higher CB1 and CB2 receptor expression in G-CSF-untreated and G-CSF-treated groups compared with MSCs. MNCs but not MSCs expressed CB1 and CB2 receptors based on qRT-PCR and flow cytometry. AEA- and 2-AG-stimulated HSC migration was blocked by eCB receptor antagonists in an in vitro migration assay. In conclusion, components of the eCB system and their interaction with Adr $\beta$ subtypes were demonstrated on HSCs and MSCs of G-CSF-treated and G-CSF-untreated healthy donors in vitro, revealing that eCBs might be potential candidates to enhance or facilitate G-CSF-mediated HSC migration under stress conditions in a clinical setting. (C) 2018 ISEH - Society for Hematology and Stem Cells. Published by Elsevier Inc. All rights reserved.
\end{abstract}

Hematological malignancies are currently treated with hematopoietic stem cell transplantation (HSCT) [1]. Rapid and sustained recovery of hematopoietic functions after HSCT correlates with the number of $\mathrm{CD} 34^{+}$hematopoietic stem cells $\left(\mathrm{CD} 34^{+} \mathrm{HSCs}\right)$ infused [2]. CD34 ${ }^{+} \mathrm{HSCs}$ reside mainly in the bone marrow (BM) microenvironment(s) and mobilize to the peripheral blood (PB) after administration of growth factors or antagonists, such as granulocyte colony-stimulating factor

Offprint requests to: Petek Korkusuz, MD, PhD, Department of Histology and Embryology, Faculty of Medicine, Hacettepe University, Ankara 06100, Turkey; E-mail: petek@ haccettepe.edu.tr

Supplementary data related to this article can be found online at https:// doi.org/10.1016/j.exphem.2017.09.009.
(G-CSF). The release mechanism of these cells from the hematopoietic microenvironment is still not completely understood [3,4]. Infection and stress increase HSC migration through lipopolysaccharide (LPS) release [5] and activation of the sympathetic nervous system via $\beta$-adrenergic receptors $(\operatorname{Adr} \beta 1, \operatorname{Adr} \beta 2$, and $\operatorname{Adr} \beta 3)$ [6,7] in a circadian rhythm [8]. However, they may not be the only regulators of HSC migration [9]. Chemokine stromal derived factor-1 (SDF1, also termed CXCL12) and its major receptor, CXCR4, are crucial in mediating both retention and mobilization of HSCs. G-CSF and the CXCR4 antagonist AMD3100 are the only U.S. Food and Drug Administration-approved agents for patients when HSCs fail to mobilize [10]. G-CSF-based migration requires a multiday dosing regimen and is associated 
with some morbidity and rare but serious complications [11].

Endocannabinoids (eCBs) are endogenous lipid mediators generated by many cell types both in the brain and peripheral tissues and activate the cannabinoid receptors $\mathrm{CB} 1$ and CB2. The eCBs, in particular anandamide (AEA; full agonist for $\mathrm{CB} 1$ and $\mathrm{CB} 2$ ) and 2-arachidonoylglycerol (2AG; full agonist for CB2, weak agonist for CB1), are modulators of cell proliferation, differentiation, apoptosis, and migration $[12,13]$. Cannabinoid receptor expression was reported on macrophage, erythroid, B-lymphoid, T-lymphoid, and mast cell lines [14] and rodent BM- HSCs and mesenchymal stem cells (MSCs) [15]. Cannabinoid-receptormediated cell migration has been investigated in murine myeloid leukemia cells [16], mice BM mononuclear cells (MNCs) [17], and BM- HSCs [18], embryonic kidney cells [19], mouse microglial cells [20], and endothelial cells [21].

The sympathetic activation and the subsequent betaadrenergic system involvement is well described in BM under physiologic and stress conditions, but it is not the only/ efficient stimulator for HSC mobilization. eCBs functioning as neurotransmitters and paracrine factors may play role in HSC mobilization similar to mobilization induced as a result of stress-induced sympathetic hyperactivity in the human BM microenvironment. Therefore, the utility of eicosanoidbased therapeutic strategies including cannabinoids is being investigated but still requires further investigation for improving HSC mobilization [6-8,22,23]. Here, we assessed the following: (1) if healthy donor HSCs and MSCs release eCBs (AEA and 2-AG) and express $\mathrm{CB} 1$ and $\mathrm{CB} 2$ receptors, (2) if HSCs migrate toward eCBs and MSCs, and (3) if there is a difference between cells obtained from donors after G-CSF treatment.

The aim of the present study was to elucidate the role of the eCB system in the human BM microenvironment on migration of HSCs and the effects of G-CSF thereon. We found expression of eCBs in stromal $\mathrm{BM}$ microenvironments and cannabinoid receptors in HSCs. HSC migration in the presence of the eCB ligands (AEA and 2-AG) increased compared with controls and decreased in presence of the eCB receptor antagonists AM281 and AM630. Therefore, eCBs may be a novel candidate to enhance or facilitate/accelerate G-CSFmediated HSC mobilization in a clinical setting.

\section{Methods}

\section{Cell culture}

Use of human material was approved by the Hacettepe University Local Ethical Committee (GO13/170-17). Age-matched BM aspirations were obtained from G-CSF-untreated $(n=10)$ or treated $(n=10)$ healthy donors (average ages: $15.1 \pm 10.2$ years in G-CSFuntreated donors; $12.4 \pm 7.6$ years for the G-CSF-treated group) scheduled to serve as donors for transplantation purposes. MNCs were obtained by density gradient centrifugation using Biocoll (\#L6113/5, Merck-Millipore, Germany). CD34 ${ }^{+}$HSCs were isolated using magnetic activated cell sorting using a human CD34
MicroBead Kit (\#130-046-702, Miltenyi Biotec, Germany). MNCs were plated in culture flasks in cell proliferation medium (DMEMLG \#11885084; Invitrogen) supplemented with $10 \%$ fetal bovine serum (\#10500064; Invitrogen), 1\% L-glutamine (\#25030081; Invitrogen), 10,000 U/mL penicillin-streptomycin (\#15140122; Invitrogen) to obtain MSCs. Third-passage human MSCs were characterized with respect to their morphology, adherence to the culture plate, expression of surface antigens, and differentiation assays $(n=10)$ [24-27].

\section{LC-ESI-MS/MS}

2-AG and AEA levels were measured in BM, PB plasma, and MSC supernatant by liquid chromatography-tandem electrospray ionization-mass spectrometry (LC-ESI-MS/MS) (\#LCMS-8030, Shimadzu, Japan) following the optimization protocol with standards (protocol adopted from Bradshaw et al [28].). The daily calibration curves were used for quantification of AEA and 2-AG; all samples were just prepared before the run and analyzed twice. The solvent controlled validation results are shown as Supplementary Fig. E1 (online only; available at www.exphem.org). The experiment was performed with 10 independent samples for each group. Polymeric sorbent-based solid-phase extraction (SPE) cartridges (Strata-X0.5 mL) were used for high-throughput sample preparation. Briefly, $250 \mu \mathrm{L}$ of BM and PB plasma or $7 \mathrm{~mL}$ of the supernatant of $7 \times 10^{6}$ MSCs were passed through the cartridges activated with methanol. Cartridges were washed with a water:methanol mixture (45:55, v/v) and elution of 2-AG (\#8923, Sigma-Aldrich, Germany) and AEA (\#A0580, Sigma-Aldrich, Germany) was performed with $2 \mathrm{~mL}$ of $\mathrm{MeOH}$. The calibration curves of 2-AG and AEA were constructed with the peak area of the analyte versus the concentration. The chromatographic separation was achieved on a $\mathrm{C}_{18}$ column (Hypersill ODS4, $50 \times 3.0 \mathrm{~mm}, 2.1 \mu \mathrm{m}$ ) using a mobile phase consisting of acetonitrile containing $0.1 \%$ formic acid and water containing $0.1 \%$ formic acid at $0.3 \mathrm{~mL} / \mathrm{min}$ flow rate.

\section{Flow cytometry}

$\mathrm{CB} 1, \mathrm{CB} 2$, and $\operatorname{Adr} \beta 1, \operatorname{Adr} \beta 2$, and $\operatorname{Adr} \beta 3$ levels were measured in BM-MSCs, BM-MNCs, and BM- CD34 ${ }^{+}$HSCs of G-CSF-treated and G-CSF-untreated donors by flow cytometry (FC). The experiment was performed with 10 independent samples for each group. In addition, $\mathrm{CD} 34^{+}$peripheral blood stem cells (PBSCs) collected from G-CSF-stimulated donors after apheresis were assessed. Live BM-MNCs were selected by density gradient centrifugation method [29,30]. Cells were permeabilized using permeabilizing solution 2 (\#340973, BD Biosciences, USA) before eCB receptor labeling by FC. Direct immunofluorescence assay was performed using ratanti-human CB1 (\#ab92764, Abcam, UK), CB2 (\#10010712, Cayman, USA), Adr $\beta 1$ (\#ABIN 669358, Antibodies Online, USA), Adrß2 (\#81578, Santa Cruz Biotechnology, USA), and CD34 and CD38 (\#560710 and \#555462, BD Biosciences, USA). Indirect immunofluorescence assay was done for $\mathrm{Adr} \beta 3$ with rabbit-primary anti-human Adrß3 (\#1472, Santa Cruz Biotechnology) and rabbit FITC-conjugated anti-goat secondary antibody (\#ab97099, Abcam). After exclusion of death cells by gating, live cells were measured with a FACSAria flow cytometer (Becton Dickinson, USA) and analyzed using BD FACS-Diva software version 6.1.2 with 10,000 list mode events recorded for each sample by ruling out the background labeling with isotype controls. 


\section{qRT-PCR}

CNR1, CNR2 (genes for CB1 and CB2, respectively), ADRB1, $A D R B 2$, and $A D R B 3$ (genes for $\operatorname{Adr} \beta 1, \operatorname{Adr} \beta 2$, and $\operatorname{Adr} \beta 3$, respectively) expression levels were measured in MNCs and MSCs of both groups by quantitative reverse transcription polymerase chain reaction (qRT-PCR). The experiment was performed with six independent samples for each group and three repeats for each sample. Total RNA was isolated from MNCs and MSCs using the RNAeasy mini RNA isolation kit (\#74104, Qiagen, USA) following the manufacturer's instructions. Total RNA concentrations and ratios were determined by spectrophotometry (Nanodrop 2000, Thermo Fisher Scientific, USA) and stored at $-80^{\circ} \mathrm{C}$. cDNA was generated from 200 ng of total RNA using the ProtoScript ${ }^{\circledR}$ First Strand cDNA synthesis kit (\#E6300, New England BioLabs, USA) following the manufacturer's instructions. qRT-PCR was performed with the PowerUp ${ }^{\mathrm{TM}}$ SYBR ${ }^{\circledR}$ Green Master Mix (\#A25741, Thermo, USA) using the ViiA ${ }^{\mathrm{TM}} 7$ Real-Time PCR System (Thermo, USA). Relative mRNA expression analysis was calculated by delta delta $\mathrm{Ct}$ method and ViiA ${ }^{\mathrm{TM}} 7$ Software (version 1.2.4).

\section{Transwell assay}

For Transwell assays CD $34^{+}$PBSCs were used. To set a migration standard, CD $34^{+}$PBSCs were placed onto prewetted filters of the polycarbonate membrane Transwells with a $5 \mu \mathrm{m}$ pore size (\#3421, Corning, USA) with $100 \mu \mathrm{L}$ of DMEM-HG (\#D5671, SigmaAldrich, Germany) medium. SDF-1 (200 ng/mL; American Research Products, USA) and norepinephrine (NE, $1 \mu \mathrm{g} / \mathrm{mL}$; Sigma-Aldrich, Germany) were added to the lower wells of the coculture system with or without their antagonists (AMD3100, $25 \mu \mathrm{g} / \mathrm{mL}$; SR59230A $2.5 \mu \mathrm{mol} / \mathrm{L}$; both Sigma-Aldrich, Germany).

For the migration assay itself, CD $34^{+}$PBSCs were placed onto prewetted filters of Transwells with $100 \mu \mathrm{L}$ of high-glucose Dulbecco's modified Eagle medium (DMEM-HG). DMEM-HG containing SDF-1, the cannabinoid agonists AEA and 2-AG (both at $30 \mathrm{nmol} / \mathrm{L}, 1 \mu \mathrm{mol} / \mathrm{L}, 50 \mu \mathrm{mol} / \mathrm{L}$; Sigma-Aldrich, Germany) with or without AM281 and AM630 (both at $10 \mu \mathrm{mol} / \mathrm{L}$; Tocris Bioscience, UK) were added to the lower wells alone or combined with LPS-stimulated or LPS-unstimulated MSCs in $600 \mu \mathrm{L}$ of DMEMHG. Cells were allowed to migrate for $4 \mathrm{~h}$ at $37^{\circ} \mathrm{C}$ in a humidified atmosphere with $5 \% \mathrm{CO}_{2}$. Filters were then removed from the chambers and counting was performed with Turk's solution. All Transwell assay experiments were performed with six independent PBSC donors and three repeats for each donor.

\section{Statistical analysis}

Descriptive results were presented as mean \pm SEM and median (minimum-maximum). Normality of the distribution of variables in every study group was evaluated by the Shapiro-Wilk test and differences between study groups (with nonparametric distribution) were assessed by Wilcoxon's test. $p$ values $<0.05$ were considered statistically significant.

\section{Results}

MSCs from G-CSF-treated and G-CSF-untreated donors are phenotypically and morphologically similar

MSCs showed plastic adherence and fibroblastic morphology; positive expression for CD73, CD44, CD90, and CD29; and were negative for hematopoietic markers, including CD34 and CD45, in the G-CSF-untreated and G-CSF-treated group, respectively (Figs. 1A and 1B). Expression of MSC markers was similar in the G-CSF-untreated and G-CSF-treated groups ( $p \geq 0.05$; Fig. 1B). Adipogenic differentiation was confirmed by morphology and the amount of Oil Red O (Figs. 1C and 1E). Osteogenic differentiation was confirmed by morphology using Alizarin Red $\mathrm{S}$ and the production of calcium phosphates (Figs. 1D and 1E). G-CSF-treated and G-CSF-untreated MSCs exhibited similar adipogenic and osteogenic differentiation capacity ( $p \geq 0.05$ ). The morphological, differentiation, and immunophenotypic characteristics confirmed stromal and multipotential nature of the MSCs used in this study [31].

\section{Endogenous AEA and 2-AG was found in $B M$ and $P B$ plasma and MSC supernatant}

MSCs secrete 2-AG and AEA in culture supernatants. AEA was detected in PB and BM plasma of G-CSF-treated and G-CSF-untreated groups at similar levels (Table 1). However, the 2-AG level in PB of the G-CSF-treated group was significantly higher compared with the BM plasma samples ( $p=0.01$; Table 1). The 2-AG level was higher in PB plasma compared with AEA in both groups, but the difference was not statistically significant (Table 1). MSCs of G-CSFtreated and G-CSF-untreated groups exhibited a similar profile of AEA and 2-AG secretion with PB and BM cells (Table 1).

\section{BM-MNCs and CD34+HSCs express CB1 and CB2 receptor and Adr $\beta$ subtypes}

MNCs and CD34+ cells expressed significantly higher levels of $\mathrm{CB} 1$ and $\mathrm{CB} 2$ receptors compared with MSCs of those groups ( $p=0.001$ for all groups) by FC (Fig. 2). CB1

Table 1. MSCs secrete AEA and 2-AG; the PB and BM niches contain AEA and 2-AG

\begin{tabular}{|c|c|c|c|c|}
\hline & \multicolumn{2}{|c|}{ G-CSF-Untreated Group } & \multicolumn{2}{|c|}{ G-CSF-Treated Group } \\
\hline & $\mathrm{AEA}(\mathrm{nmol} / \mathrm{L})$ & 2-AG (nmol/L) & $\operatorname{AEA}(\mathrm{nmol} / \mathrm{L})$ & 2-AG (nmol/L) \\
\hline PB Plasma & $\begin{array}{c}80.99 \\
(20.1-188.93)\end{array}$ & $\begin{array}{c}131.08 \\
(42.58-1631.76)\end{array}$ & $\begin{array}{c}62.09 \\
(58.12-178.21)\end{array}$ & $\begin{array}{c}1655.23 \\
(325.41-1816.14)^{*}\end{array}$ \\
\hline BM Plasma & $\begin{array}{c}77.76 \\
(7.69-286.42)\end{array}$ & $\begin{array}{c}70.38 \\
(9.27-402.84)\end{array}$ & $\begin{array}{c}17.42 \\
(5.1-534.3)\end{array}$ & $\begin{array}{c}30.7 \\
(5.94-400.99)\end{array}$ \\
\hline MSC Supernatant & $\begin{array}{c}5.62 \\
(1.07-10.63)\end{array}$ & $\begin{array}{c}2.24 \\
(0.77-6.13)\end{array}$ & $\begin{array}{c}3.92 \\
(1.44-8.67)\end{array}$ & $\begin{array}{c}1.45 \\
(0.63-12.88)\end{array}$ \\
\hline
\end{tabular}

AEA and 2-AG levels were measured by LC/ESI/MS-MS. Data are presented by median (minimum-maximum). In the G-CSF-treated group, the level of 2-AG was found to be higher in PB plasma than in BM plasma $\left({ }^{*} p<0.05, n=10\right.$ for each group; *comparison of PB vs BM for G-CSF-treated group). 
A

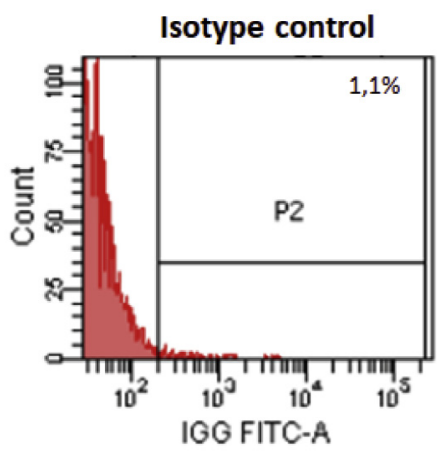

Isotype control
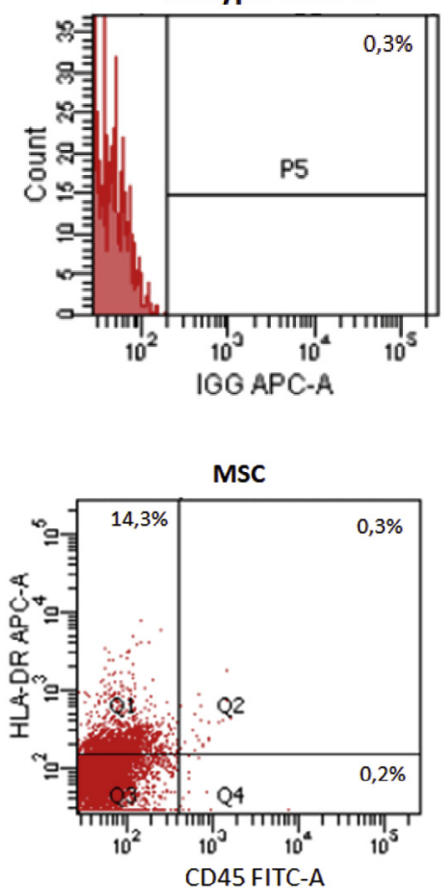

Isotype control

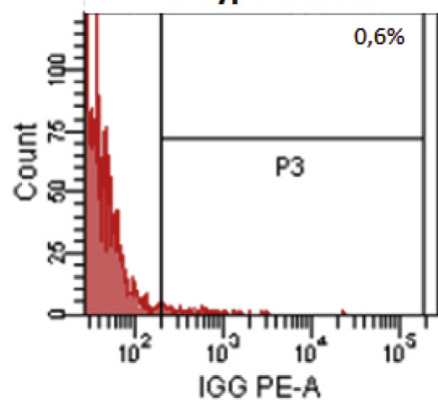

MSC

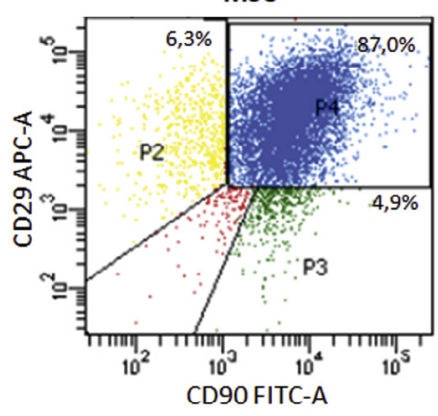

MSC

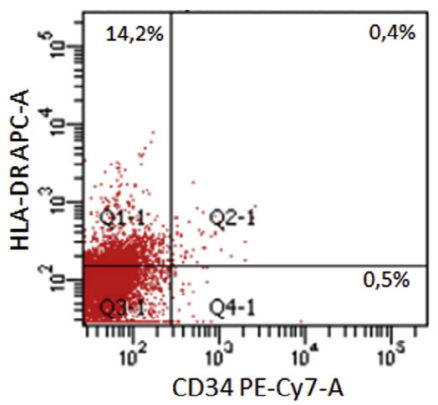

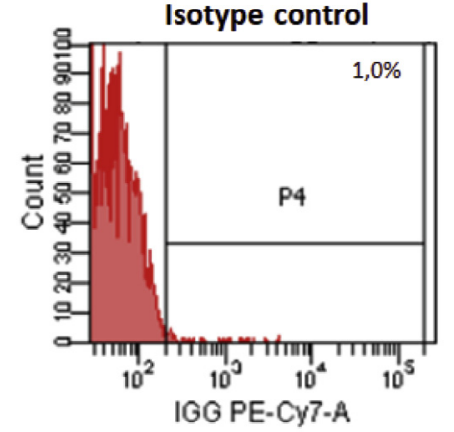

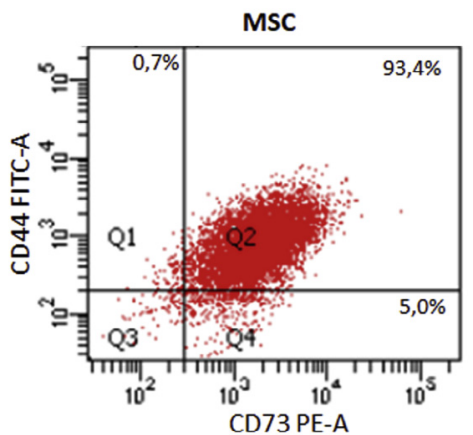

B

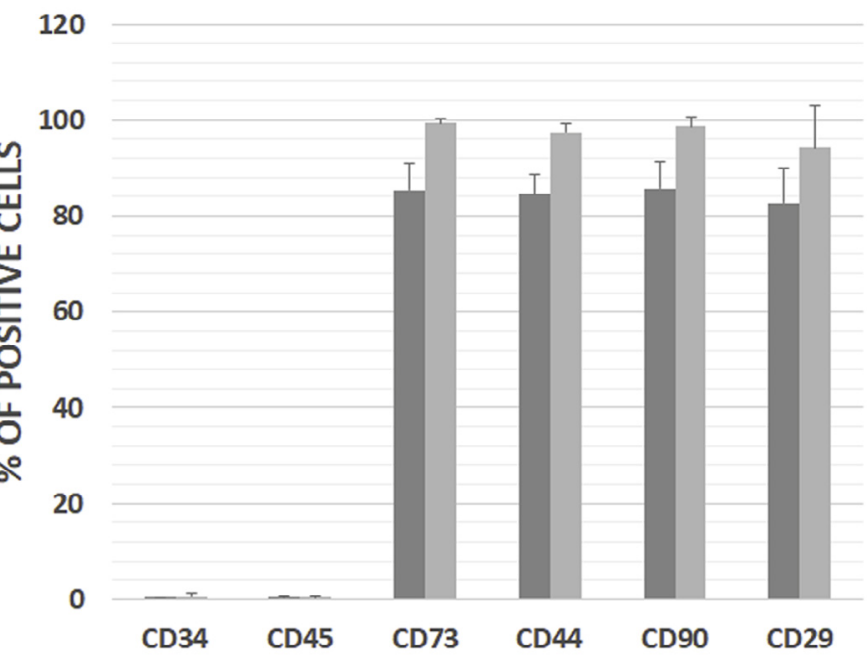

Figure 1. Characterization of human BM-MSCs. Stromal and multipotential nature of MSCs were confirmed morphologically, immuno-phenotypically, and through differentiation. (A) Representative histograms showing specific markers for MSCs by FC. FITC = fluoro-isothiocyanate; PE = phycoerythrin; $\mathrm{APC}=$ allophycocyanin; PE-Cy7 = PE-Cyanin 7. Shown are conjugated antibodies or their isotypes. (B) Bar graphic showing the percentage of negative (CD34, CD45) and positively (CD73, CD44, CD90, CD29) labeled MSCs in G-CSF-untreated and G-CSF-treated groups ( $n=10$ for each group). (C) Oil Red O (ORO) staining for adipogenic cells (inverted microscope, Olympus, 10×) and (D) Alizarin Red S (ARS) for osteogenic cells (inverted microscope, Olympus,

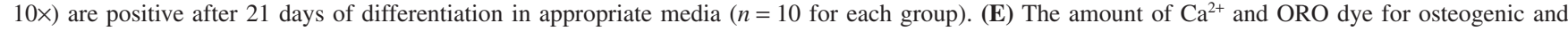
adipogenic differentiation of MSCs respectively ( $n=10$ for each group) was measured semiquantitatively. 

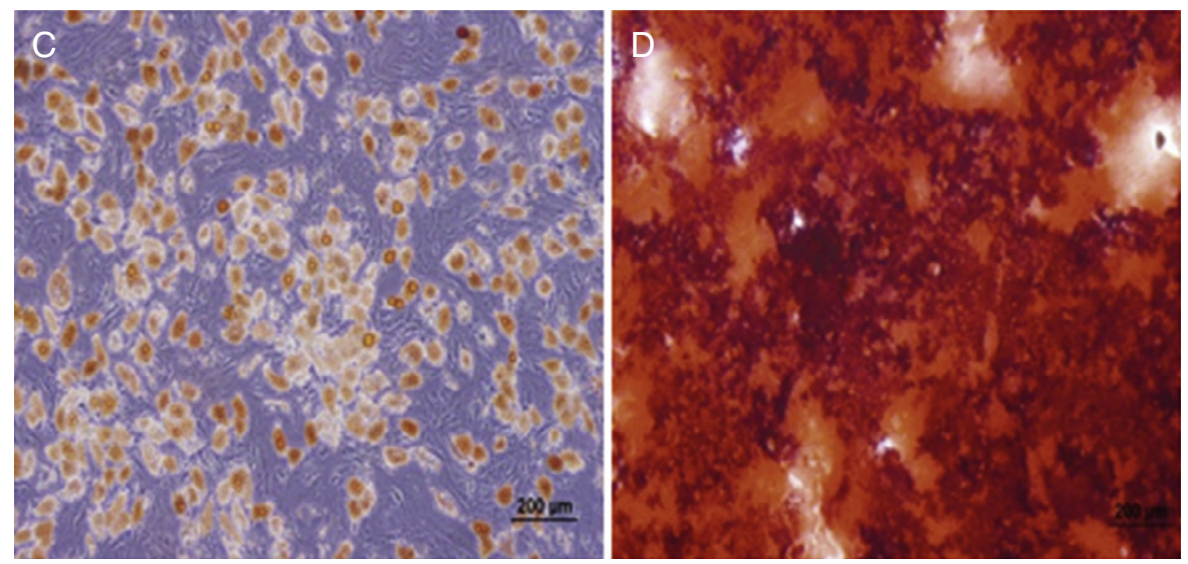

E

\begin{tabular}{lcc} 
& G-CSF untreated group & G-CSF treated group \\
\hline $\mathrm{Ca}^{2+}(\mathrm{mg} / \mathrm{dL})$ & $15,79 \pm 5,1$ & $16,97 \pm 3,7$ \\
ORO dye $(\mathrm{mg} / \mathrm{mL})$ & $1,89 \pm 1,3$ & $1,97 \pm 1,5$
\end{tabular}

Figure 1. (continued)

receptor expression was highest on $\mathrm{CD} 34^{+}$HSCs. This difference was significant for the G-CSF-untreated group only ( $p=0.02$; Fig. 2A). Data were confirmed by qRT-PCR, with which $\mathrm{CB} 1$ and $\mathrm{CB} 2$ gene expressions were detected in MNCs, but not in MSCs (Figs. 2B and 2C). CB2 expression of MNCs was higher in the G-CSF-untreated group compared with the treated group ( $p=0.04$; Fig. 2B).

MNCs, CD34 ${ }^{+} \mathrm{HSCs}$, and MSCs expressed various subtypes of Adr $\beta$ subtypes by FC; however, MNCs and MSCs mainly expressed Adr $\beta 2$, as confirmed by qRT-PCR (Fig. 2). MNCs and CD34 $4^{+}$HSCs exhibited significantly higher expression of $\operatorname{Adr} \beta 2(p=0.02$ and $p=0.004$ for MNC; $p=0.001$ and $p=0.001$ for $\mathrm{CD} 34^{+} \mathrm{HSCs}$ in the G-CSF-untreated and G-CSF-treated groups, respectively) compared with MSCs by FC (Fig. 2A). CD34 $4^{+}$HSCs exhibited higher expression for $\operatorname{Adr} \beta 2$ and $\operatorname{Adr} \beta 3$ in all groups compared with MNCs, but the difference was only significant for $\operatorname{Adr} \beta 3$ ( $p=0.001$ and $p=0.013$ for MNC; $p=0.001$ and $p=0.002$ for MSC in the G-CSF-untreated and G-CSF-treated groups, respectively) (Fig. 2A). Increased Adr 32 expression was found in G-CSF-treated MNCs compared with untreated $(p=0.02)$ MNCs by qRT-PCR (Fig. 2B). Differences in expression of Adr $\beta 1$ as measured by FC were not found.

\section{CD34+ PBSC migration toward SDF-1, NE, AEA, and}

\section{2-AG is blocked by specific antagonists}

CD34 ${ }^{+}$PBSCs were characterized by high expression of CD34 $(87.9 \pm 4.5 \%)$ and CD38 (35.5 $\pm 12.4 \%)$ and dual expression of CD34/CD38 (33.0 $\pm 12.7 \%)$ before the Transwell assay. The cells were also checked for Adr $\beta$ subtypes and CB 1 and $\mathrm{CB} 2$ receptor expression (Fig. 3A). To test $\mathrm{CD} 34^{+} \mathrm{PBSC}$ migration, we established a Transwell/coculture assay (Fig. 3B), in which we showed migration of $\mathrm{CD} 34^{+}$PBSCs toward
SDF-1 and NE. SDF-1 and NE antagonists (AMD3100 and SR59230A, respectively) inhibited migration (Fig. 3C). CD34 PBSCs effectively migrated toward AEA and 2-AG. CB1 and CB2 receptor antagonists specifically blocked this effect (Fig. 3D). The CD $34^{+}$PBSCs exhibited significantly higher migration to $30 \mathrm{nmol} / \mathrm{L}$ and $50 \mu \mathrm{mol} / \mathrm{L}$ doses of AEA, respectively, compared with SDF-1 $(p=0.027$ and $p=0.028$, respectively; Fig. 3D). AM281 and AM630 significantly inhibited migration of these doses of AEA ( $p=0.028$ for $30 \mathrm{nmol} / \mathrm{L}$ and $p=0.027$ for $50 \mu \mathrm{mol} / \mathrm{L}$, respectively; Fig. 3D). The CD34 ${ }^{+}$PBSCs exhibited significantly higher migration toward all doses of 2-AG compared with SDF-1 ( $p=0.027$, $p=0.027$ and $p=0.028$, respectively; Fig. 3D). AM281 and AM630 significantly inhibited CD34 $4^{+}$PBSC migration at all doses of 2 -AG $(p=0.027$ and $p=0.027$ for $30 \mathrm{nmol} / \mathrm{L}$, $p=0.028$ and $p=0.027$ for $1 \mu \mathrm{mol} / \mathrm{L}, p=0.028$ and $p=0.026$ for $50 \mu \mathrm{mol} / \mathrm{L}$, respectively; Fig. 3D).

\section{PBSCs migration toward MSCs is blocked by CB receptor and $\beta$-AR antagonists}

CD $34^{+}$PBSCs effectively migrated toward LPS-stimulated and LPS-unstimulated MSCs in the coculture system (Figs. 3B and 3E). However, the LPS-stimulated MSCs exhibited higher eCB-receptor-mediated migration stimulation compared with unstimulated cells. The CB1 antagonist AM281 $(p=0.03)$, the CXCR4 antagonist AMD3100 ( $p=0.05)$, and the Adr $\beta$ inhibitor SR59230A ( $p=0.03)$ all significantly blocked migration toward LPS-stimulated MSCs (Fig. 3E). The difference was not significant for the CB2 antagonist AM630 (Fig. 3E). Inhibition of migration toward LPS-unstimulated MSCs was not significant. The LPS-only control group revealed a response at the baseline with almost no migrating $\mathrm{CD} 34^{+}$ PBSCs. 

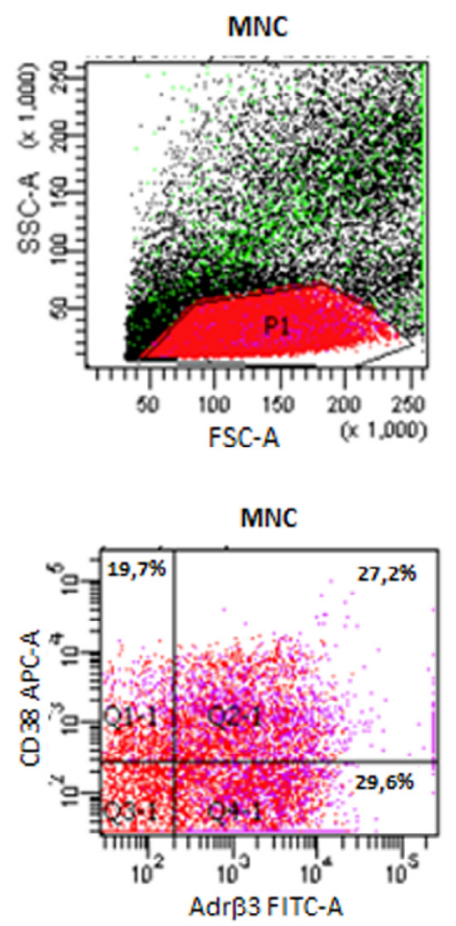

B

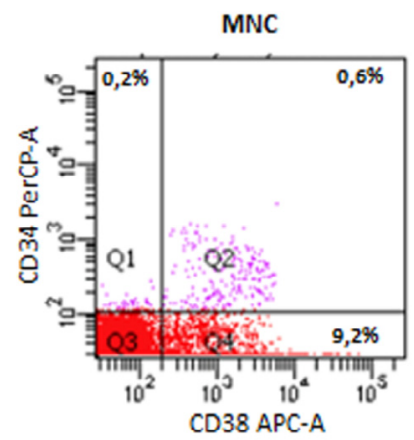

CD34+ cells

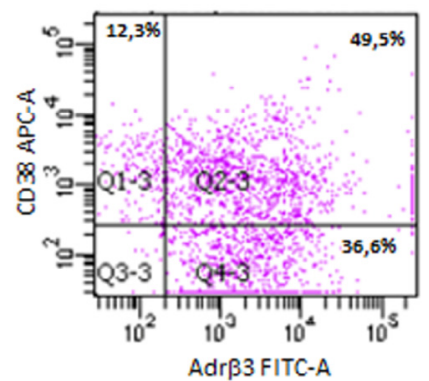

MNC

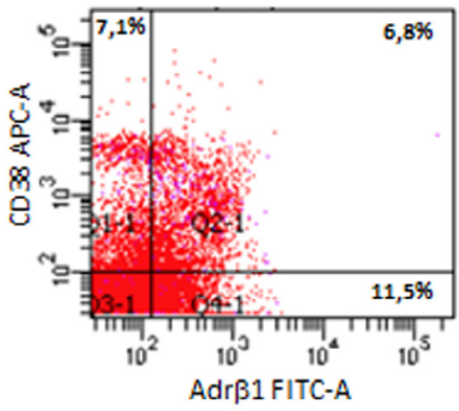

MNC

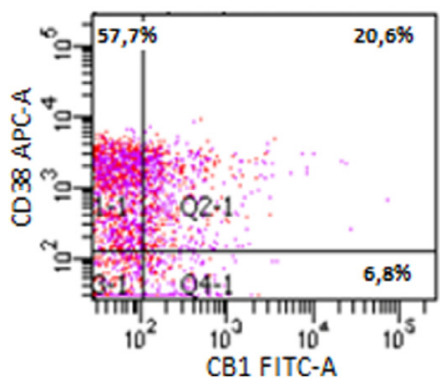

CD34+ cells

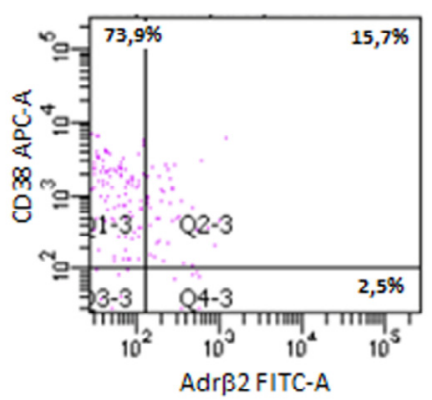

CD34+ cells

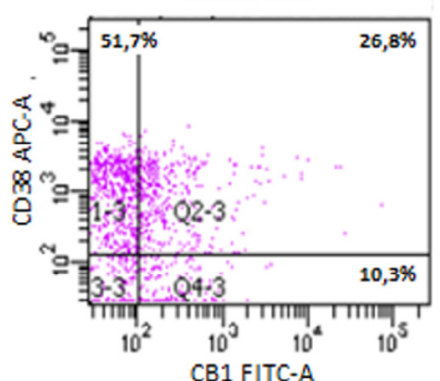

MNC

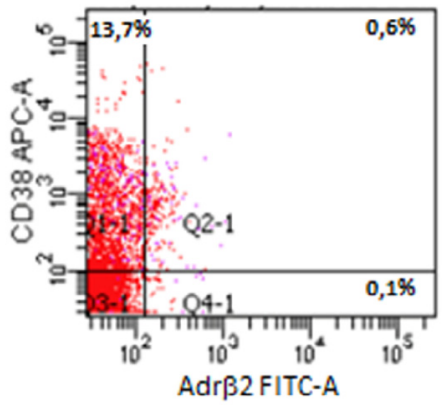

MNC

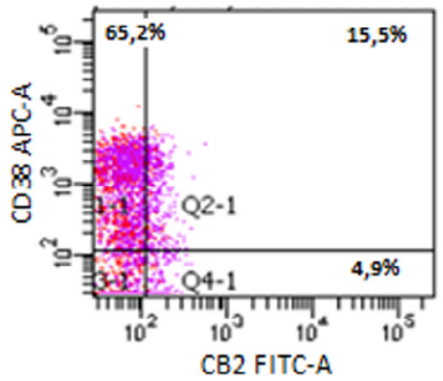

CD34+ cells

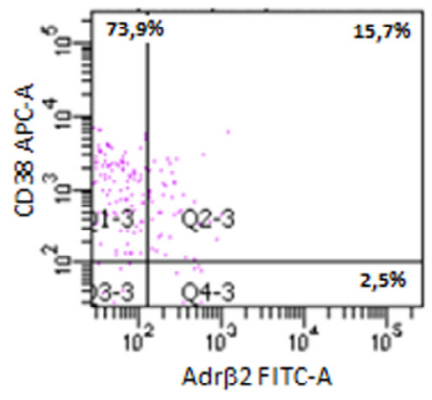

CD34+ cells

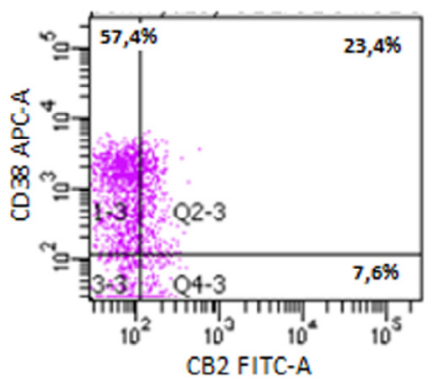

Figure 2. BM-MNCs and CD34+ HSCs express CB1, CB2, and various subtypes as shown by FC and qRT-PCR. (A) Representative histograms showing specific markers for MNCs obtained after density gradient centrifugation method. Monocyte/lymphocyte/stem cell fraction (as gated in P1) of the MNCs were used for receptor analysis ( $n=10$ for each group). (B) Representative histograms showing specific markers for CD34 $4^{+}$HSCs (Q1 + Q2 quadrants on the first graphic) by FC ( $n=10$ for each group). (C) Representative histograms showing specific markers for BM MSCs by FC. MSCs were gated according to their own FSC/SSC plot ( $n=10$ for each group). (D) Bar graphic showing the percentage of MNCs, MSCs, and CD34 ${ }^{+} \mathrm{HSCs}$ expressing Adr $\beta 1$, Adr $\beta 2$, and Adr $\beta 3$ and CB1 and CB2 receptors as determined by FC. The MNCs and CD34+ HSCs express significantly higher levels of CB1 and CB2 receptors in G-CSF-untreated and G-CSF-treated groups compared with MSCs. CD $34^{+}$HSCs exhibit higher expression of Adr $\beta 2$ and Adr $\beta 3$ in all groups compared with MNCs, but the difference is only significant for $\operatorname{Adr} \beta 3$ ( $n=10$ for each group). (E,F) qRT-PCR analysis revealing CB1 and CB2 gene expressions on MNCs, but not on MSCs. MNCs and MSCs mainly express Adr $\beta 2$ ( $n=6$ for each group). FITC $=$ fluoro-isothiocyanate; $\mathrm{PE}=$ phycoerythrin; $\mathrm{APC}=$ allophycocyanin; $\mathrm{PE}-\mathrm{Cy} 7=\mathrm{PE}-\mathrm{Cyanin} 7$. Shown are conjugated antibodies or their isotypes $(\# p<0.05)$. 
C

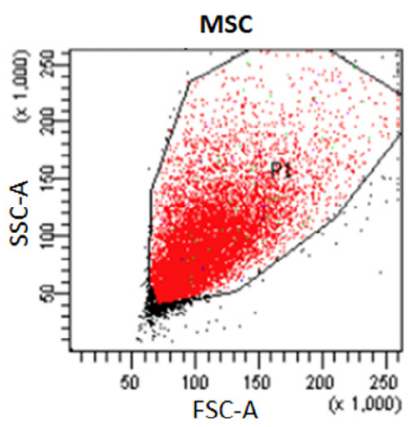

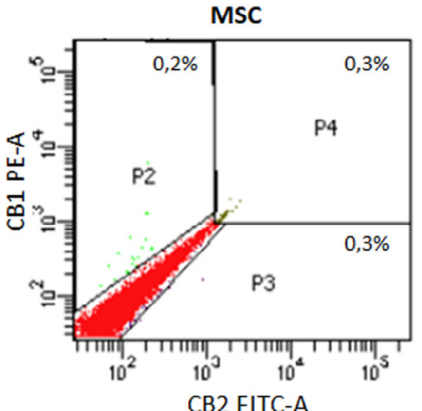
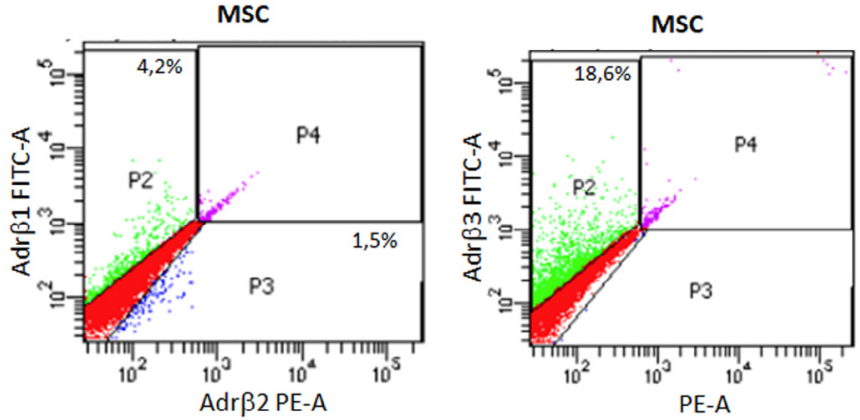

D
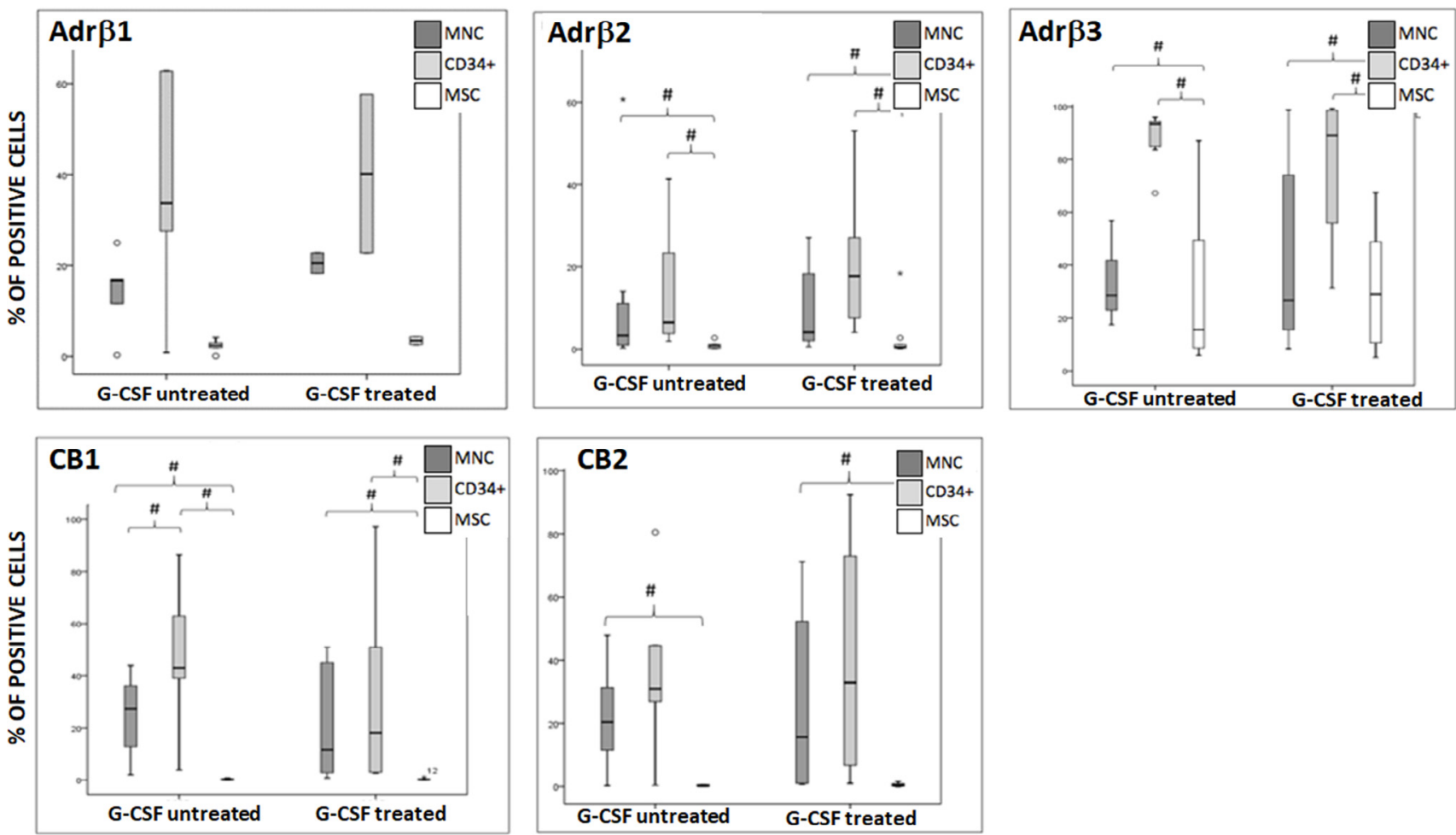

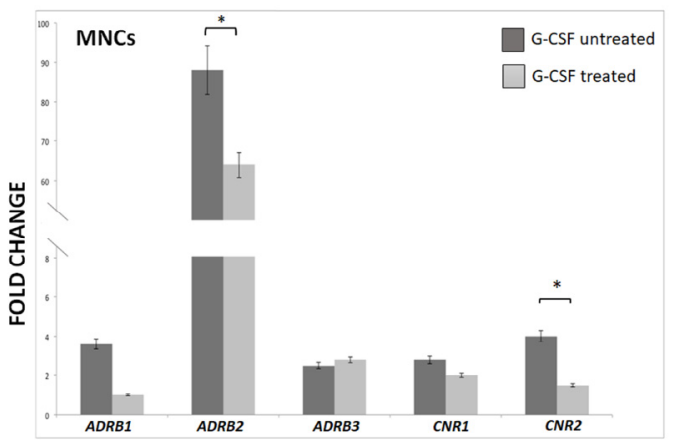

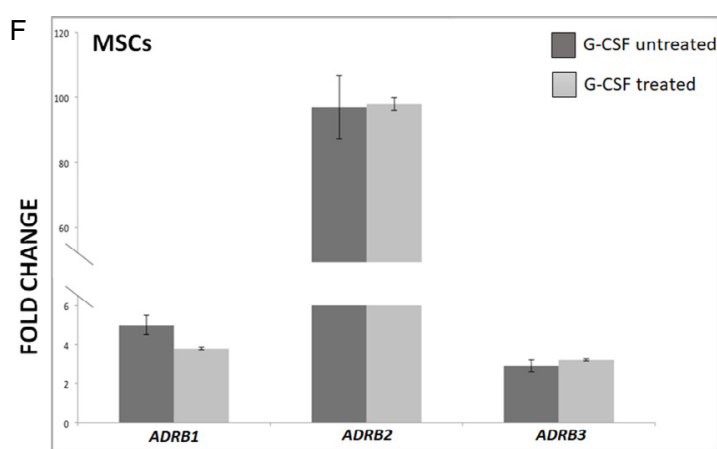

Figure 2. (continued)

\section{Discussion}

Secretion of eCBs in the stromal BM microenvironment and cannabinoid receptors on HSCs was assessed in G-CSFtreated and G-CSF-untreated donors in this study. We showed that eCBs act as mobilizers of CD $34^{+}$PBSCs through CB1 and $\mathrm{CB} 2$ receptors in vitro. Our results demonstrated that the eCBs AEA, and 2-AG secreted by MSCs increase human CD34+ PBSC migration dose dependently toward LPSstimulated MSCs. MSCs play important roles in the BM microenvironment and modulate HSC mobilization and 
A

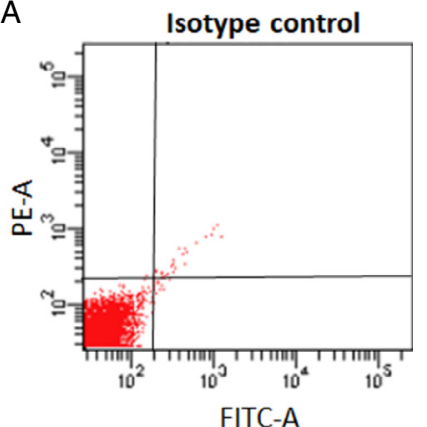

PBSC

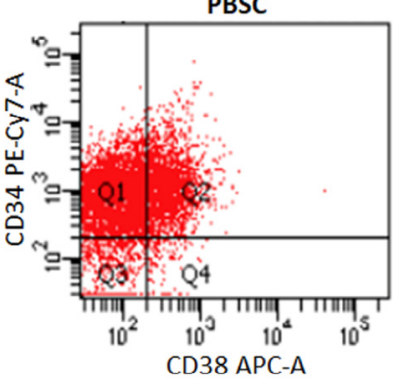

CD34+PBSC

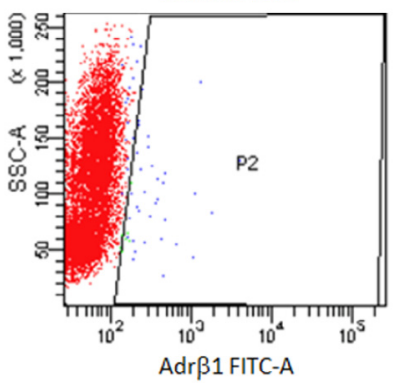

Isotype control

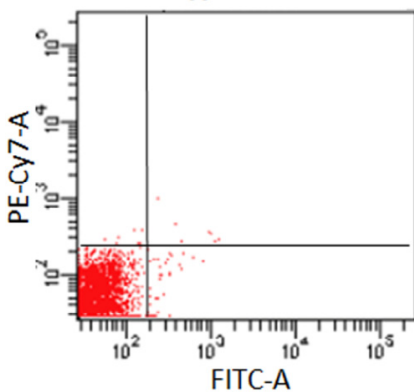

CD34+ PBSC

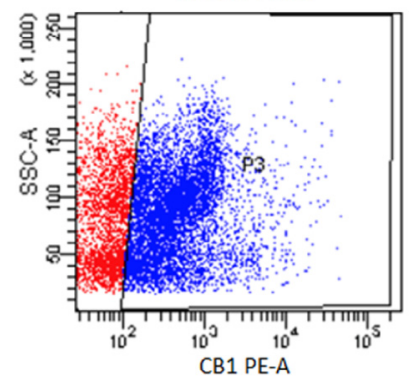

CD34+ PBSC

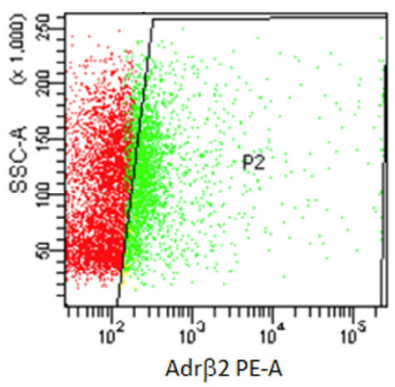

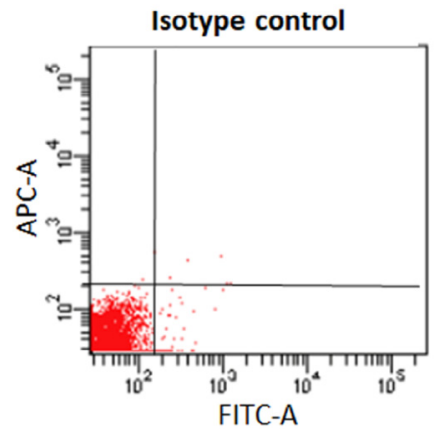

FITC-A
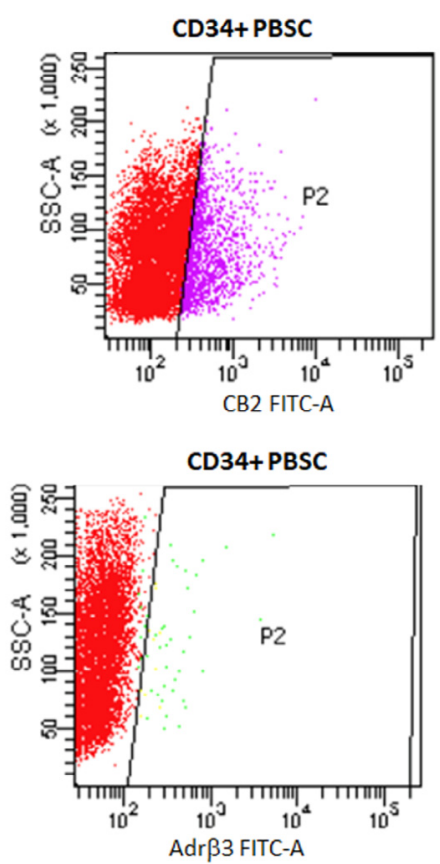

B

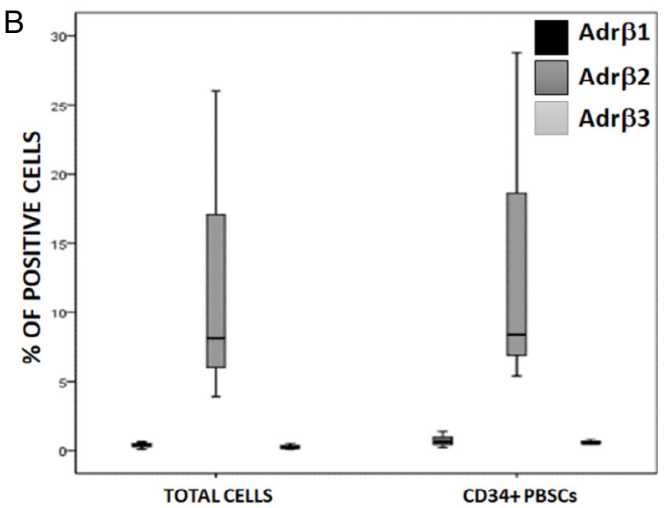

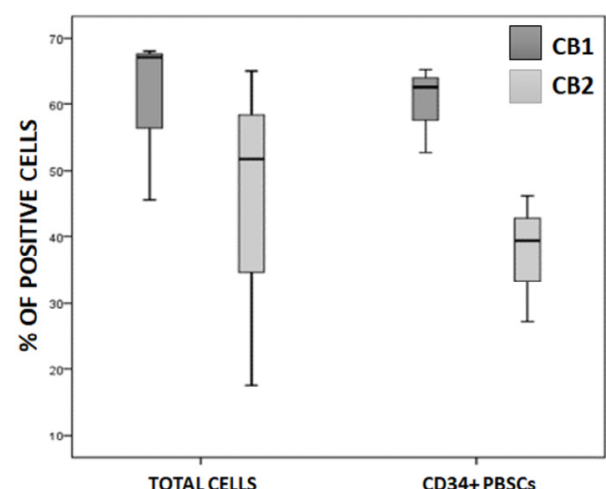

TOTAL CELLS

CD34+ PBSCs

Figure 3. AEA and 2-AG stimulate CD34+ PBSC migration to MSCs and this migration effect is blocked by Adr $\beta$ and CB receptor antagonists. (A) Representative histograms showing isotype controls and specific markers for CD34 ${ }^{+} \mathrm{PBSCs}(\mathrm{Q} 1+\mathrm{Q} 2$ quadrants on fourth graphic) by FC ( $n=6$ for each group). (B) Characterization of PBSCs and $\mathrm{CD} 34^{+}$cells from apheresis product for the $\beta$-AR and CB receptors by FC $(n=6)$. The cells expressed Adr $\beta$ subtypes and the CB receptors. (C) Experimental design for Transwell migration assay. The Transwell/coculture system allows CD34 ${ }^{+}$PBSC migration toward SDF-1, norepinephrine, AEA, 2-AG, or MSCs, respectively. (D) CD34 ${ }^{+}$PBSC migration toward SDF-1 and NE are inhibited by the specific antagonists AMD3100 and SR59230A, respectively $(n=6)$. (E) Migration of $\mathrm{CD} 34^{+}$PBSCs to the eCBs AEA and 2-AG. CD34 ${ }^{+}$PBSCs exhibited significantly higher migration to $30 \mathrm{nmol} / \mathrm{L}$ and $50 \mu \mathrm{mol} / \mathrm{L}$ doses of AEA and $30 \mathrm{nmol} / \mathrm{L}, 1 \mu \mathrm{mol} / \mathrm{L}$, and $50 \mu \mathrm{mol} / \mathrm{L}$ doses of $2-\mathrm{AG}$ compared with SDF-1. This migration effect is blocked by CB antagonists $\left({ }^{*} p<0.05, n=6\right.$ ). (F) CD34 ${ }^{+}$PBSCs effectively migrated toward LPS-stimulated (LPS ${ }^{+}$) and unstimulated (LPS-) MSCs. The LPS-only control group is not presented because it is at the base line. The migration effect is blocked by the CB1 antagonist AM281, the CXCR4 antagonist AMD3100, and the Adr $\beta$ blocker SR59230A significantly $\left({ }^{*} p<0.05, n=6\right.$ ). FITC $=$ fluoro-isothiocyanate PE $=$ phycoerythrin; $\mathrm{APC}=$ allophycocyanin $; \mathrm{PE}-\mathrm{Cy} 7=\mathrm{PE}-\mathrm{Cyanin}$ 7. Shown are conjugated antibodies or their isotypes. 
C

Transwell Migration Assay

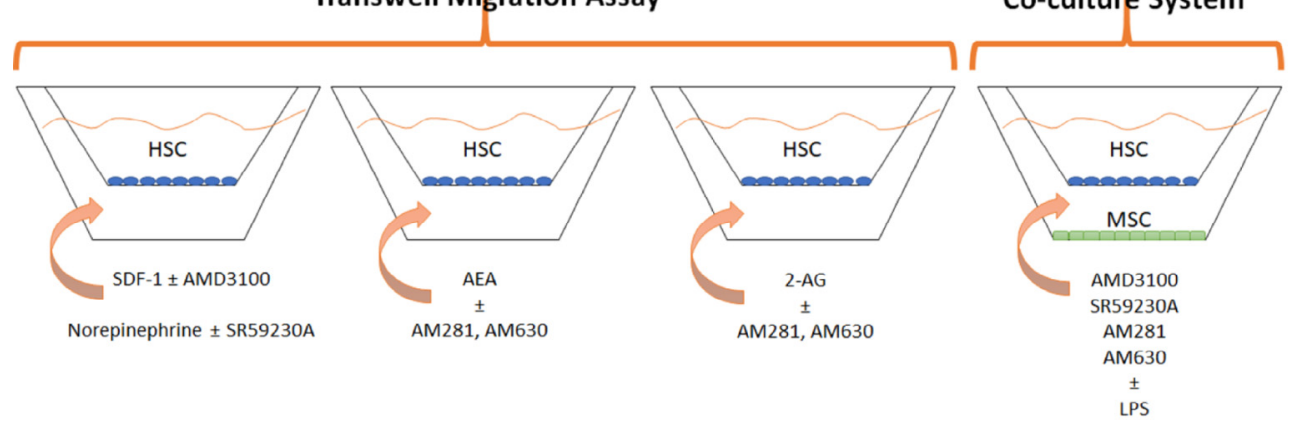

D

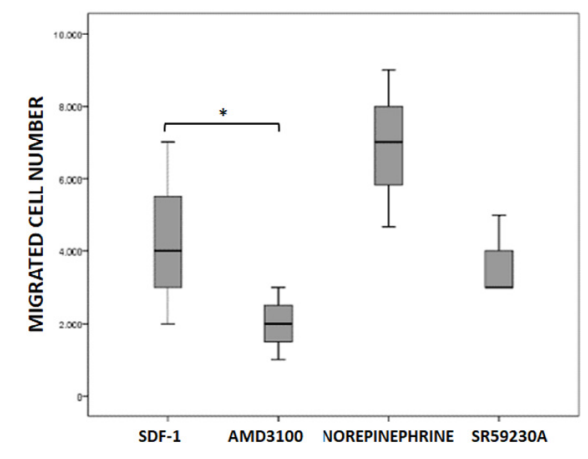

E
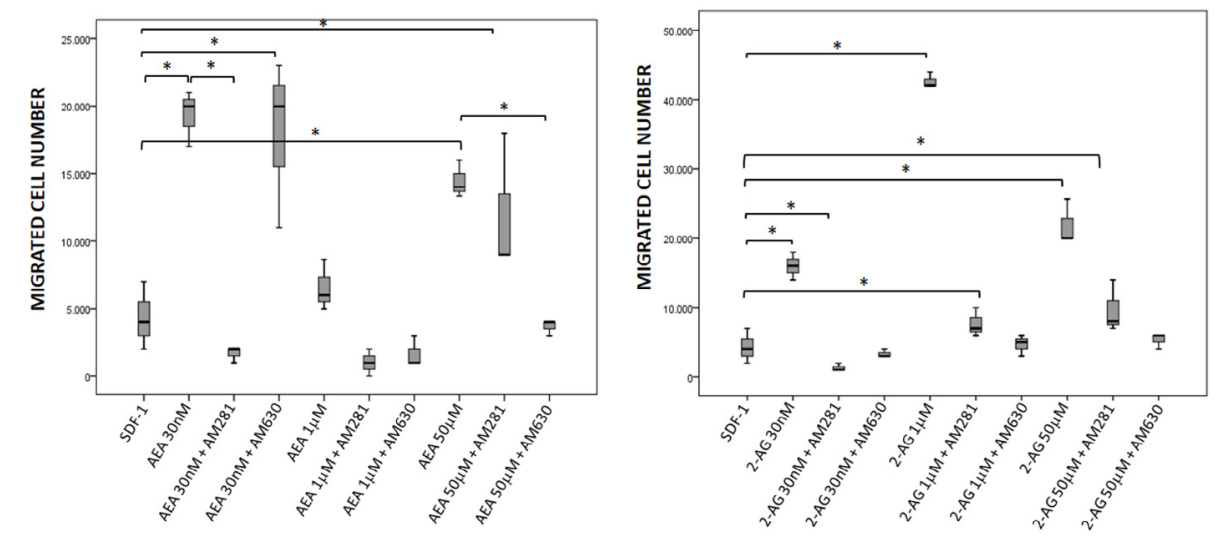

F
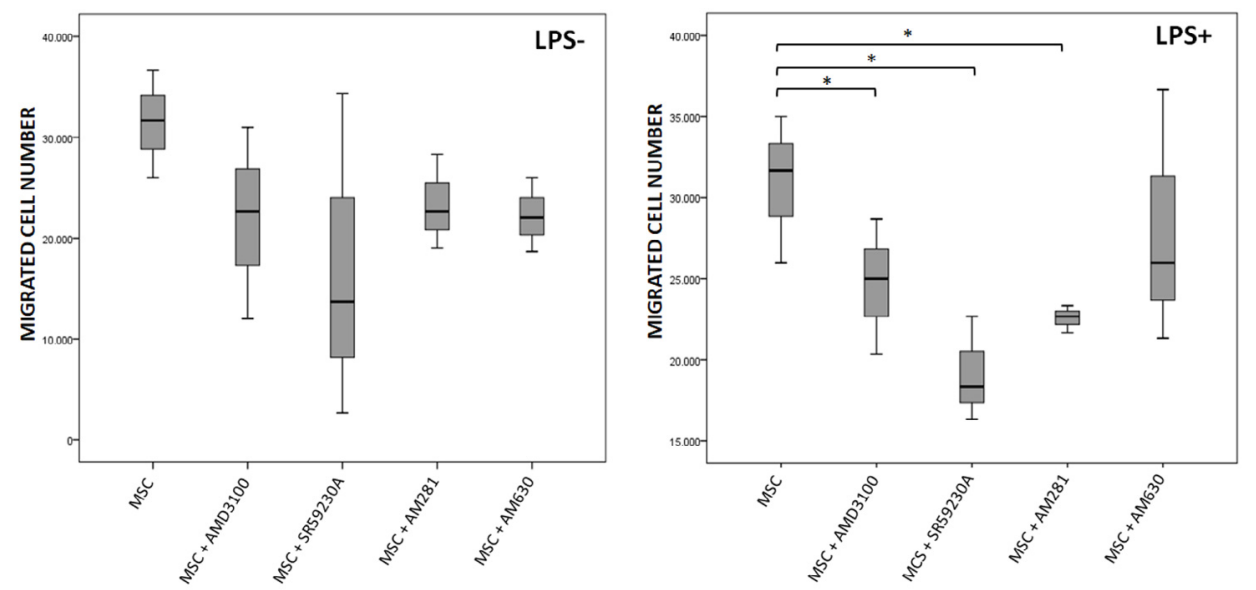

Figure 3. (continued) 
survival [32] under stress conditions, which results in sympathetic $\operatorname{Adr} \beta$ stimulation [6,7]. In this study, AEA and 2-AG caused $\mathrm{CD} 34^{+} \mathrm{PBSC}$ migration, reflecting migration via the $\beta$-adrenergic system. BM-HSCs and MSCs express $\operatorname{Adr} \beta 2$ and $\operatorname{Adr} \beta 3$ [33]. Adr $\beta$ signaling and LPS release favor the positive effect of G-CSF on HSC mobilization $[6,34]$.

$\mathrm{PB}$ and BM plasma and MSC supernatants contained AEA and 2-AG. AEA and 2-AG levels in the PB plasma of healthy controls were found previously to be $0.8 \pm 0.12$ and $19.0 \pm 2.61 \mathrm{nmol} / \mathrm{L}$, respectively, using LC-ESI-MS/MS [35]. Levels of AEA and 2-AG in PB were previously found to be $0.56 \mathrm{ng} / \mathrm{mL}$ and $2,0 \mathrm{ng} / \mathrm{mL}$ in healthy donors [36]. We report levels of AEA and 2-AG of approximately 50 times higher compared with findings by Jean-Gilles et al. [35] and Quercioli et al. [36]. However, others reported a range from $\mathrm{pmol} / \mathrm{L}$ to $\mu \mathrm{mol} / \mathrm{L}$ levels for AEA and 2-AG at a different matrix [37] (Human Metabolite Data Base, www.hmdb.ca). AEA levels $(0.36 \pm 0.14 \mathrm{ng} / \mathrm{mL})$ and $2-\mathrm{AG}(6.26 \pm 2.10 \mathrm{ng} / \mathrm{mL})$ were also measured in PB plasma of patients during traumatic stress exposure and posttraumatic stress disorder [38]. Our study on AEA and 2-AG levels in PB plasma of G-CSF-treated and G-CSF-untreated donors correlated well with that study. eCB levels were not examined in BM plasma of humans or other species previously. AEA levels in BM and PB plasma were generally equivalent between G-CSF-treated and G-CSFuntreated donors in our study. The 2-AG level was higher in PB plasma compared with BM plasma in the G-CSF-treated group. The 2-AG level in PB increased approximately 10fold after G-CSF treatment compared with the untreated group. This may suggest a potential function for 2-AG during G-CSF treatment.

Rossi and colleagues [39] reported a gradual decrease in AEA and 2-AG levels secreted by human BM-MSCs from passage 1 (AEA: $5 \mathrm{pmol} / \mathrm{mg}$ protein and 2-AG: $11 \mathrm{pmol} /$ $\mathrm{mg}$ protein $2-\mathrm{AG}$, at passage 1 ). In our study, we used passage 1 MSCs to assess CD34 ${ }^{+}$PBSC migration. Human adipose tissue-derived MSCs have been reported to secrete AEA and 2-AG (AEA: $3.5 \mathrm{pmol} / \mathrm{mg}$ protein and 2-AG: $7.3 \mathrm{pmol} / \mathrm{mg}$ protein) [40]. These findings were consistent with our results showing AEA and 2-AG secretion by BM-MSCs. Therefore, endogenous eCBs found in BM plasma samples are likely to be secreted by MSCs.

Here, we report for the first time the distribution of eCB receptor and $\mathrm{Adr} \beta$ subtypes on human BM and PB cells simultaneously with or without stimulation by G-CSF. We found significantly higher $\mathrm{CB} 1$ and $\mathrm{CB} 2$ receptor expression on MNCs and CD $34^{+}$HSCs compared with MSCs. There are limited studies reporting distribution of $\mathrm{CB} 1$ and/or CB2 receptors on HSCs $[14,15]$. Although CB1 receptor expression is reported in a single murine T-lymphoid cell line, CB2 receptor expression was found in a multitude of myeloid, macrophage, erythroid, B/T-lymphoid, mast cell lines [14]. In rodents, $\mathrm{CB} 1$ and $\mathrm{CB} 2$ receptors were detected in $\mathrm{BM}$ MSCs and HSCs [15].
Here, Adr $\beta$ subtypes were detected on MNCs, CD34 $4^{+}$ HSCs, and MSCs of both G-CSF-treated and G-CSF-untreated samples at similar levels. CD $34^{+}$HSCs displayed the highest level of $A d r \beta 2$ expression. These $\operatorname{Adr} \beta$ distribution data correlate with previous data $[6,7,22,23,41,42]$. Adr $\beta 2$ was determined by FC and confocal microscopy in mouse BMHSCs $\left(\mathrm{Lin}^{-}, \mathrm{Scal}^{+}, \mathrm{CD} 117^{+}\right)$[22]. Functional studies assessing $\operatorname{Adr} \beta$ antagonists showed that $\operatorname{Adr} \beta 2$ and $\operatorname{Adr} \beta 3$ stimulation increase migration of rat hematopoietic progenitor cells (HPCs) [23], mouse HSCs, and HPCs [6]. Exogenous NE administration promotes human $\mathrm{CD} 34^{+}$HPC proliferation and migration via $\operatorname{Adr} \beta 2$ [7].

Activation of $\operatorname{Adr} \beta 2$ and $\operatorname{Adr} \beta 3$ on BM-MSCs downregulate SDF-1 and regulate G-CSF-induced migration of HPCs in mice [41]. Monitoring of SDF-1 levels in the $\mathrm{BM}$ can be used directly as an indicator for mobilization of HSCs to the PB [42]. Therefore, we tested migration of CD34 ${ }^{+}$PBSCs toward NE and SDF-1. We showed that CD34 ${ }^{+}$PBSCs exhibited significantly higher migration toward AEA and 2-AG compared with SDF-1. eCBs stimulate HSC migration via both $\mathrm{CB} 1$ and $\mathrm{CB} 2$ receptors. In our study, we determined our dose range for AEA and 2-AG according to their $K_{\mathrm{i}}$ values for CB1 and CB2 receptors and the related literature $[16,17,19-21,43]$. AEA $(1 \mu \mathrm{mol} / \mathrm{L})$ and $2-\mathrm{AG}$ (300 nmol/L and $1 \mu \mathrm{mol} / \mathrm{L}$ ) act as chemoattractants when applied to genetically CB2-overexpressing murine myeloid leukemia cells in a Transwell assay [16]. 2-AG and AEA (both at $0.25 \mu \mathrm{mol} / \mathrm{L}$ ) stimulated rapid migration of 8- to 12-weekold mice BM-MNCs in vitro [17]. HU-210, WIN55212-2, and AEA (at $50 \mu \mathrm{mol} / \mathrm{L}$ ), three CB1 receptor agonists with distinct chemical structures, induced migration of human $C B 1$ gene-overexpressing HEK293T cells [19]. 2-AG (50 $\mu \mathrm{mol} /$ $\mathrm{L})$ and AEA $(1 \mu \mathrm{mol} / \mathrm{L})$ triggered migration of $\mathrm{CB} 1$ and CB2 receptor expressing newborn mouse neopallia microglial cells and BV-2 cells (a murine microglial cell line) in a Boyden chamber assay in vitro [20]. The nonpsychoactive cannabinoid agonist abnormal cannabidiol (abn-cbd) was shown to stimulate HUVEC migration in Transwells and the effect was inhibited by the selective antagonist O1918 $(30 \mu \mathrm{mol} / \mathrm{L})$ [21]. A nonselective CB1 and CB2 agonist CP55940 (dose not indicated) addition to single dose of G-CSF treatment increased granulocyte-macrophage colony-forming unit mobilization significantly compared with G-CSF alone in BALB/c mice [18].

We report that the migratory effect of AEA (a full agonist for $\mathrm{CB} 1$ and $\mathrm{CB} 2$ ) and 2-AG (a full agonist for CB2 and a weak agonist for CB1) $[12,13]$ was generally inhibited by CB1 and CB1 receptors separately. Conversely, AEA activated CB2 receptors mainly when applied at $50 \mu \mathrm{mol} / \mathrm{L}$ and its effect wais blocked with AM630, possibly due to the high dose activation ability for and a shift to $\mathrm{CB} 2$ receptors.

In our first set of experiments, we showed higher $\mathrm{Adr} \beta 2$ and CB2 receptor expression in G-CSF-treated MNCs compared with untreated cells. We also demonstrated that AEA and 2-AG mediate $\mathrm{CD} 34^{+}$PBSC migration toward MSCs in a coculture system. LPS-stimulated MSCs exhibited higher 
eCB-receptor-mediated migration stimulation effect to $\mathrm{CD} 34^{+}$ PBSCs compared with unstimulated. Those findings were not shown previously. Human BM-MSCs endogenously secrete AEA and 2-AG, which in turn induces $\mathrm{CD} 34^{+} \mathrm{PBSC}$ migration in vitro.

Our study results are limited due to the small number of human samples used due to ethical considerations. Second, because our assay does not simulate a 3D BM niche accurately, the true mobilizing effects of eCBs on HSCs should be tested further in vivo. These limitations, however, do not constrain future in vivo and clinical studies because statistical accuracy was validated at the beginning of the study. We have demonstrated that the effects of the components of the eCB system and other mobilizing agents on the interaction of HSCs with MSCs should be further assessed in animal models and in clinical trials. In particular, the lower $\operatorname{Adr} \beta 2$ and $\mathrm{CB} 2$ receptor expression pattern in G-CSF-treated MNCs should be confirmed with high numbers of fresh donor samples immediately after treatment.

Rapid and sustained recovery of hematopoietic functions after HSCT correlates with the number of $\mathrm{CD} 34^{+} \mathrm{HSCs}$ infused. New solutions should be explored to increase the number of $\mathrm{CD} 34^{+} \mathrm{HSCs}$. The sympathetic activation and the subsequent beta-adrenergic system involvement is well described, but it is not the only/efficient stimulator for HSC mobilization. Therefore, the utility of eicosanoid-based therapeutic strategies including cannabinoids requires investigation $[8,18]$. If the mechanism of mobilization of HSCs by eCB agonists or antagonists can be controlled or regulated, then this may result in the development of clinically applicable new mobilization strategies and a better understanding of BM niche dynamics and HSCT strategies.

In conclusion, we found an important role for both the eCB systems and $\beta$-adrenergic systems in the migration of HSCs and demonstrate interactions between the HSCs and MSCs of G-CSF-treated and G-CSF-untreated healthy age-matched donors. The eCB system works well in both G-CSF-treated and G-CSF-untreated donors. Therefore, cannabinoid agonists may be strong candidates for new potential therapies of various hematological diseases.

\section{Acknowledgments}

This work was supported by grants from the Scientific and Technological Research Council of Turkey (TUBITAK; 113S819) and the Scientific Research Coordination Unit of Hacettepe University (013D04101005). Petek Korkusuz MD. $\mathrm{Ph} . \mathrm{D}$. is the corresponding author and Sevil Köse's mentor (advisor). This work contains Sevil Köse's PhD thesis data. Sevil Köse is currently an Assistant Professor at the Department of Nutrition and Dietetics, Faculty of Health Sciences, Atılım University, Ankara Turkey. All experiments were performed at the Department of Stem Cell Sciences, Institute of Health Sciences and Center for Stem Cell Research and Development (PEDI-STEM) of Hacettepe University. Statistical analyses were done by Eda Öztürk, Ph.D., at the Biostatistics Department of Hacettepe University Faculty of
Medicine. Optimization of the LC-ESI-MS/MS method was done by Assoc. Prof. Erol Şener at the Department of Analytical Chemistry, Anadolu University Faculty of Pharmacy.

\section{References}

1. Trivedi M, Martinez S, Corringham S, Medley K, Ball ED. Optimal use of G-CSF administration after hematopoietic SCT. Bone Marrow Transplant. 2009;43:895-908.

2. Singh AK, McGuirk JP. Allogeneic stem cell transplantation: a historical and scientific overview. Cancer Res. 2016;76:6445-6451.

3. Bensinger W, DiPersio JF, McCarty JM. Improving stem cell mobilization strategies: future directions. Bone Marrow Transplant. 2009;43:181-195.

4. Gertz MA. Current status of stem cell mobilization. Br J Haematol. 2010;150:647-662.

5. Burberry A, Zeng MY, Ding L, et al. Infection mobilizes hematopoietic stem cells through cooperative NOD-like receptor and Toll-like receptor signaling. Cell Host Microbe. 2014;15:779-791.

6. Katayama Y, Battista M, Kao WM, et al. Signals from the sympathetic nervous system regulate hematopoietic stem cell egress from bone marrow. Cell. 2006;124:407-421.

7. Spiegel A, Shivtiel S, Kalinkovich A, et al. Catecholaminergic neurotransmitters regulate migration and repopulation of immature human CD34+ cells through Wnt signaling. Nat Immunol. 2007;8:11231131.

8. Méndez-Ferrer S, Chow A, Merad M, Frenette PS. Circadian rhythms influence hematopoietic stem cells. Curr Opin Hematol. 2009;16:235242.

9. Lemoli RM. New strategies for stem cell mobilization. Mediterr J Hematol Infect Dis. 2012;4:e2012066.

10. Slater S. Plerixafor. J Adv Pract Oncol. 2012;3:49-54.

11. Cashen AF, Lazarus HM, Devine SM. Mobilizing stem cells from normal donors: is it possible to improve upon G-CSF? Bone Marrow Transplant. 2007;39:577-588.

12. Maccarrone M, Bab I, Bíró T, et al. Endocannabinoid signaling at the periphery: 50 years after THC. Trends Pharmacol Sci. 2015;36:277-296.

13. Jiang S, Fu Y, Avraham HK. Regulation of hematopoietic stem cell trafficking and mobilization by the endocannabinoid system. Transfusion. 2011;51(suppl 4):65S-71S.

14. Valk P, Verbakel S, Vankan Y, et al. Anandamide, a natural ligand for the peripheral cannabinoid receptor is a novel synergistic growth factor for hematopoietic cells. Blood. 1997;90:1448-1457.

15. Scutt A, Williamson EM. Cannabinoids stimulate fibroblastic colony formation by bone marrow cells indirectly via CB2 receptors. Calcif Tissue Int. 2007;80:50-59.

16. Jordà MA, Verbakel SE, Valk PJ, et al. Hematopoietic cells expressing the peripheral cannabinoid receptor migrate in response to the endocannabinoid 2-arachidonoylglycerol. Blood. 2002;99:2786-2793.

17. Patinkin D, Milman G, Breuer A, Fride E, Mechoulam R. Endocannabinoids as positive or negative factors in hematopoietic cell migration and differentiation. Eur J Pharmacol. 2008;595:1-6.

18. Hoggatt J, Pelus LM. Eicosanoid regulation of hematopoiesis and hematopoietic stem and progenitor trafficking. Leukemia. 2010;24:1993-2002.

19. Song ZH, Zhong M. CB1 cannabinoid receptor-mediated cell migration. J Pharmacol Exp Ther. 2000;294:204-209.

20. Walter L, Franklin A, Witting A, et al. Nonpsychotropic cannabinoid receptors regulate microglial cell migration. J Neurosci. 2003;23:1398_ 1405.

21. Mo FM, Offertáler L, Kunos G. Atypical cannabinoid stimulates endothelial cell migration via a Gi/Go-coupled receptor distinct from CB1, CB2 or EDG-1. Eur J Pharmacol. 2004;489:21-27.

22. Muthu K, Iyer S, He LK, et al. Murine hematopoietic stem cells and progenitors express adrenergic receptors. J Neuroimmunol. 2007; 186:27-36. 
23. Beiermeister KA, Keck BM, Sifri ZC, et al. Hematopoietic progenitor cell mobilization is mediated through beta- 2 and beta- 3 receptors after injury. J Trauma. 2010;69:338-343.

24. Köse S, Aerts Kaya F, Denkbas EB, Korkusuz P, Cetinkaya FD. Evaluation of biocompatibility of random or aligned electrospun polyhydroxybutyrate scaffolds combined with human mesenchymal stem cells. Turk J Biol. 2016;40:410-419.

25. Lotfy A, Salama M, Zahran F, Jones E, Badawy A, Sobh M. Characterization of mesenchymal stem cells derived from rat bone marrow and adipose tissue: a comparative study. Int J Stem Cells. 2014; 7:135-142.

26. Mennan C, Wright K, Bhattacharjee A, Balain B, Richardson J, Roberts $\mathrm{S}$. Isolation and characterisation of mesenchymal stem cells from different regions of the human umbilical cord. Biomed Res Int. 2013;2013:916136.

27. Alipour F, Parham A, Kazemi Mehrjerdi H, Dehghani H. Equine adipose-derived mesenchymal stem cells: phenotype and growth characteristics, gene expression profile and differentiation potentials. Cell J. 2015;16:456-465.

28. Bradshaw HB, Rimmerman N, Krey JF, Walker JM. Sex and hormonal cycle differences in rat brain levels of pain-related cannabimimetic lipid mediators. Am J Physiol Regul Integr Comp Physiol. 2006;291:R349R358.

29. Pick M, Eldor A, Grisaru D, Zander AR, Shenhav M, Deutsch VR. Ex vivo expansion of megakaryocyte progenitors from cryopreserved umbilical cord blood. A potential source of megakaryocytes for transplantation. Exp Hematol. 2002;30:1079-1087.

30. Wangen JR, Eidenschink Brodersen L, Stolk TT, Wells DA, Loken MR. Assessment of normal erythropoiesis by flow cytometry: important considerations for specimen preparation. Int J Lab Hematol. 2014;36:184-196

31. Dominici M, Le Blanc K, Mueller I, et al. Minimal criteria for defining multipotent mesenchymal stromal cells. The International Society for Cellular Therapy position statement. Cytotherapy. 2006;8:315-317.
32. Isern J, Méndez-Ferrer S. Stem cell interactions in a bone marrow niche. Curr Osteoporos Rep. 2011;9:210-218.

33. Spiegel A, Kalinkovich A, Shivtiel S, Kollet O, Lapidot T. Stem cell regulation via dynamic interactions of the nervous and immune systems with the microenvironment. Cell Stem Cell. 2008;3:484-492.

34. Maestroni GJ. Adrenergic regulation of haematopoiesis. Pharmacol Res. 1995:32:249-253.

35. Jean-Gilles L, Feng S, Tench CR, et al. Plasma endocannabinoid levels in multiple sclerosis. J Neurol Sci. 2009;287:212-215.

36. Quercioli A, Pataky Z, Vincenti G, et al. Elevated endocannabinoid plasma levels are associated with coronary circulatory dysfunction in obesity. Eur Heart J. 2011;32:1369-1378.

37. Zoerner AA, Gutzki FM, Batkai S, et al. Quantification of endocannabinoids in biological systems by chromatography and mass spectrometry: a comprehensive review from an analytical and biological perspective. Biochim Biophys Acta. 2011;1811:706-723.

38. Hauer D, Schelling G, Gola H, et al. Plasma concentrations of endocannabinoids and related primary fatty acid amides in patients with post-traumatic stress disorder. PLoS ONE. 2013;8:e62741.

39. Rossi F, Bernardo ME, Bellini G, et al. The cannabinoid receptor type 2 as mediator of mesenchymal stromal cell immunosuppressive properties. PLoS ONE. 2013;8:e80022.

40. Ivanov I, Borchert P, Hinz B. A simple method for simultaneous determination of $\mathrm{N}$-arachidonoylethanolamine, $\mathrm{N}$-oleoylethanolamine, $\mathrm{N}$-palmitoylethanolamine and 2-arachidonoylglycerol in human cells. Anal Bioanal Chem. 2015;407:1781-1787.

41. Méndez-Ferrer S, Battista M, Frenette PS. Cooperation of beta(2)- and beta(3)-adrenergic receptors in hematopoietic progenitor cell mobilization. Ann N Y Acad Sci. 2010;1192:139-144.

42. Wright DE, Bowman EP, Wagers AJ, Butcher EC, Weissman IL. Hematopoietic stem cells are uniquely selective in their migratory response to chemokines. J Exp Med. 2002;195:1145-1154.

43. Thakur GA, Nikas SP, Makriyannis A. CB1 cannabinoid receptor ligands. Mini Rev Med Chem. 2005;5:631-640. 


\section{Supplementary data}

A

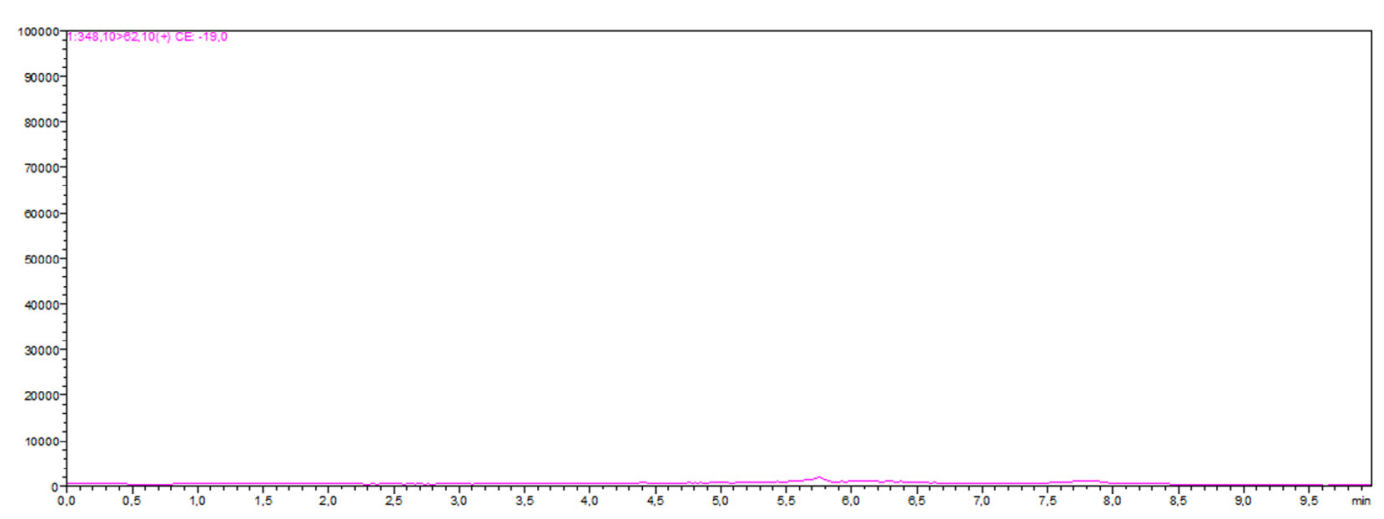

B

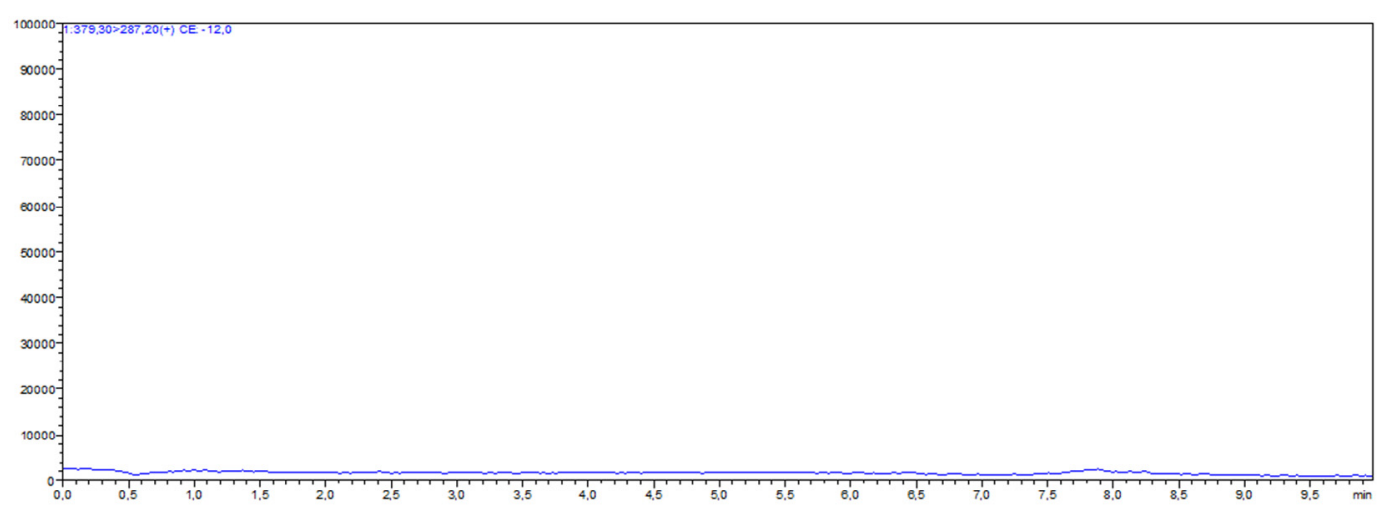

C

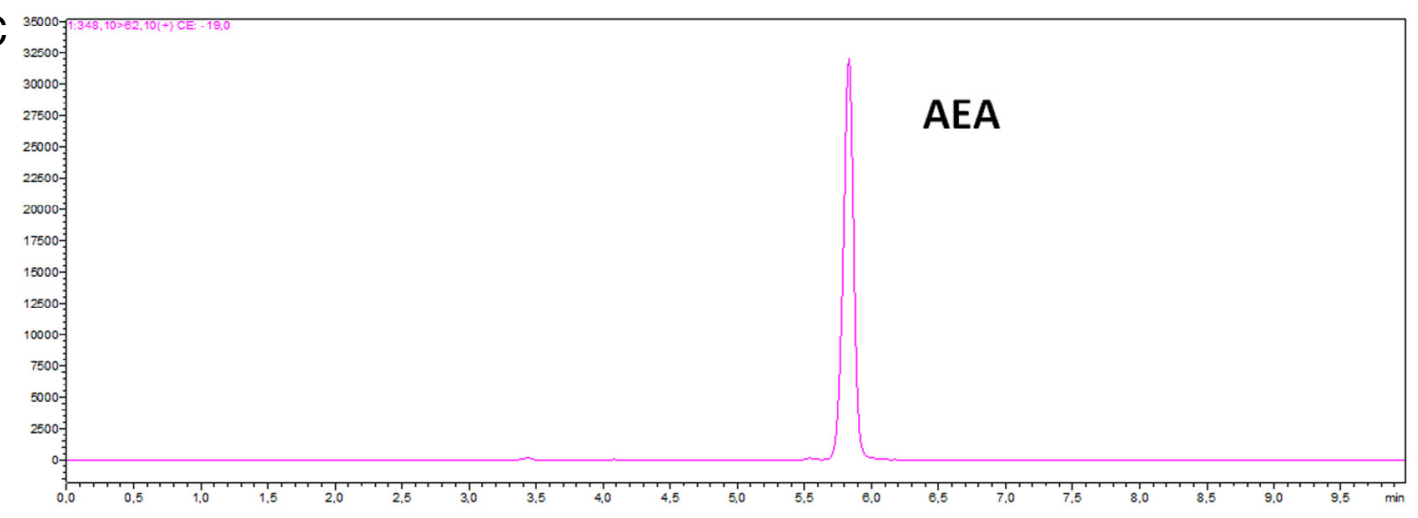

$\mathrm{D}$

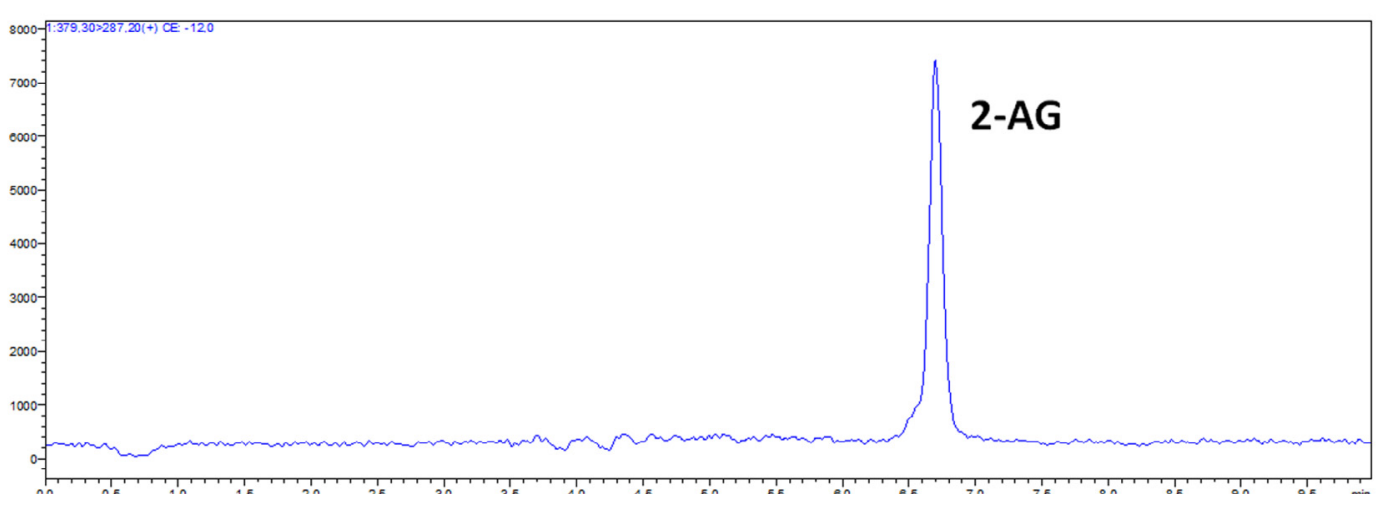

Supplementary Figure E1. The solvent controlled calibration peaks are shown for AEA and 2-AG. (A) Solvent only for AEA, (B) Solvent only for 2-AG, (C) AEA in solvent, (D) 2-AG in solvent 